\title{
Study on hardness and microstructural characteristics of sand cast Al-Si-Cu alloys
}

\author{
MUZAFFER ZEREN and ERDEM KARAKULAK* \\ Department of Metallurgical and Materials Engineering, Kocaeli University, Turkey
}

MS received 22 October 2008; revised 2 December 2008

\begin{abstract}
In this study, the influence of $\mathrm{Cu}$ content on the hardness and microstructural characteristics of sand cast $\mathrm{Al}-\mathrm{Si}-\mathrm{Cu}$ alloys have been investigated. Al-Si alloys with $2 \%$ and $5 \% \mathrm{Cu}$ have been utilized for this purpose. Solidification of $\mathrm{Al}-\mathrm{Si}-\mathrm{Cu}$ alloys have been realized by melting in a gas furnace with a crucible and casting in green sand molds at $690^{\circ} \mathrm{C}$. The solution treatment has been performed at $500^{\circ} \mathrm{C}$ for $7 \mathrm{~h}$ and then specimens were quenched in water. The samples have been aged at $190^{\circ} \mathrm{C}$ for $15 \mathrm{~h}$ to observe the effect of aging on mechanical properties.
\end{abstract}

Keywords. Al-Si-Cu alloys; $\mathrm{Cu}$ content; microstructure; heat-treatment.

\section{Introduction}

Aluminium and its alloys represent an important category of materials due to their high technological value and wide range of industrial applications, especially in aerospace and household industries. Mainly because of their good specific strength, excellent formability and corrosion resistance, Al-Si base alloys are most commonly used in commercial aluminum casting alloys and have been used extensively in automotive, aerospace and transportation industries. $\mathrm{Al}-\mathrm{Si}-\mathrm{Cu}$ alloy system has great importance in casting industry. Copper is a potent precipitation-strengthening agent in aluminium. $\mathrm{Cu}$ additions up to about $5 \%$ lead to alloys with very high strength and good toughness when subject to natural or artificial aging. The addition of $\mathrm{Cu}$ increases considerably the strength of $\mathrm{Al}-\mathrm{Si}$ alloys, due to precipitation of dispersed $\mathrm{Al}_{2} \mathrm{Cu}(\theta)$ phase during aging. The strengthening contribution from precipitation is typically a function of both precipitate size and fraction (Haque and Maleque 1998; Wang et al 2003; Li R X et al 2004; Li X et al 2004; Guo and Shah 2005; Zeren 2005; Kim and Buchheit 2007; Rosliza et al 2008).

Determining the influence of $\mathrm{Cu}$ content on the hardness and microstructural characteristics of sand cast $\mathrm{Al}-\mathrm{Si}-\mathrm{Cu}$ alloys is the aim of this study.

\section{Experimental}

Two different $\mathrm{Cu}$ containing $\mathrm{Al}-\mathrm{Si}$ alloys were utilized for this study. The chemical compositions of these alloys can be seen in table 1 . The melting operation was carried

\footnotetext{
*Author for correspondence (erdemkarakulak@kocaeli.edu.tr)
}

out on a gas furnace in a crucible, and the molten metal was cast into green sand molds at $690^{\circ} \mathrm{C}$.

For understanding heat treatment effect on microstructure and mechanical properties, solution and aging heat treatments were applied to the solidified specimens. Solution heat treatment was performed at $500^{\circ} \mathrm{C}$ for $7 \mathrm{~h}$. After that specimens were water quenched to obtain super saturated solid solution structure. The specimens were then aged at $190^{\circ} \mathrm{C}$ for $15 \mathrm{~h}$. All heat treatments were carried out with a resistance heating furnace.

To obtain the transition temperatures of the equilibrium phases, differential thermal analysis (DTA) was performed with a NETZSCH STA 409 PC7PG. The cooling rates during the DTA was constant at $30 \mathrm{~K} / \mathrm{min}$. And all tests were applied under argon atmosphere.

Specimens were prepared in usual manner for metallographic observations. Microstructural investigations were made by a Zeiss optical microscope and Jeol 6063 type Scanning Electron Microscope (SEM) with an Energy Dispersive X-ray Spectroscopy (EDX) attachment.

\section{Results and discussion}

\subsection{Microstructure}

Figure 1 shows the optical micrographs of as-cast A2 alloy. As seen in figure 1(a) alloy has dendritic $\alpha$-Al matrix with dispersed needle-like eutectic silicon particles. In figure 1(b) some dark contrasted intermetallic particles are seen. To identify these intermetallic phases back-scattered electrons are used in SEM, which can be seen in figure 2 for A5 alloy. In SEM micrographs $\mathrm{Cu}$ containing intermetallic precipitates appear in white contrast and can easily be separated. 
Figure 3 shows the EDX analysis of the precipitate arrowed in figure 2(b). The EDX analysis proves that the precipitate contains $\mathrm{Cu}$. The chemical composition of the intermetallic particle is $\mathrm{Al}_{2} \mathrm{Cu}$ which is generally named as $\theta$ phase for $\mathrm{Al}-\mathrm{Cu}$ alloys.

\subsection{Differential thermal analysis (DTA)}

Figures 4 and 5 show the DTA curves for $\mathrm{Al}-\mathrm{Si}-2 \mathrm{Cu}$ and $\mathrm{Al}-\mathrm{Si}-5 \mathrm{Cu}$, respectively. In the DTA curve of alloy containing $5 \% \mathrm{Cu}$ there is a peak (marked as 1 ) which is

Table 1. Chemical composition of alloys.

\begin{tabular}{lccccc}
\hline & \multicolumn{5}{c}{ Composition (wt.\%) } \\
\cline { 2 - 6 } Alloy & $\mathrm{Si}$ & $\mathrm{Cu}$ & $\mathrm{Mg}$ & $\mathrm{Fe}$ & $\mathrm{Al}$ \\
\hline A2 & $10 \cdot 8$ & 2 & $0 \cdot 1$ & $0 \cdot 8$ & Balance \\
A5 & $10 \cdot 6$ & 5 & $0 \cdot 1$ & $0 \cdot 6$ & Balance \\
\hline
\end{tabular}
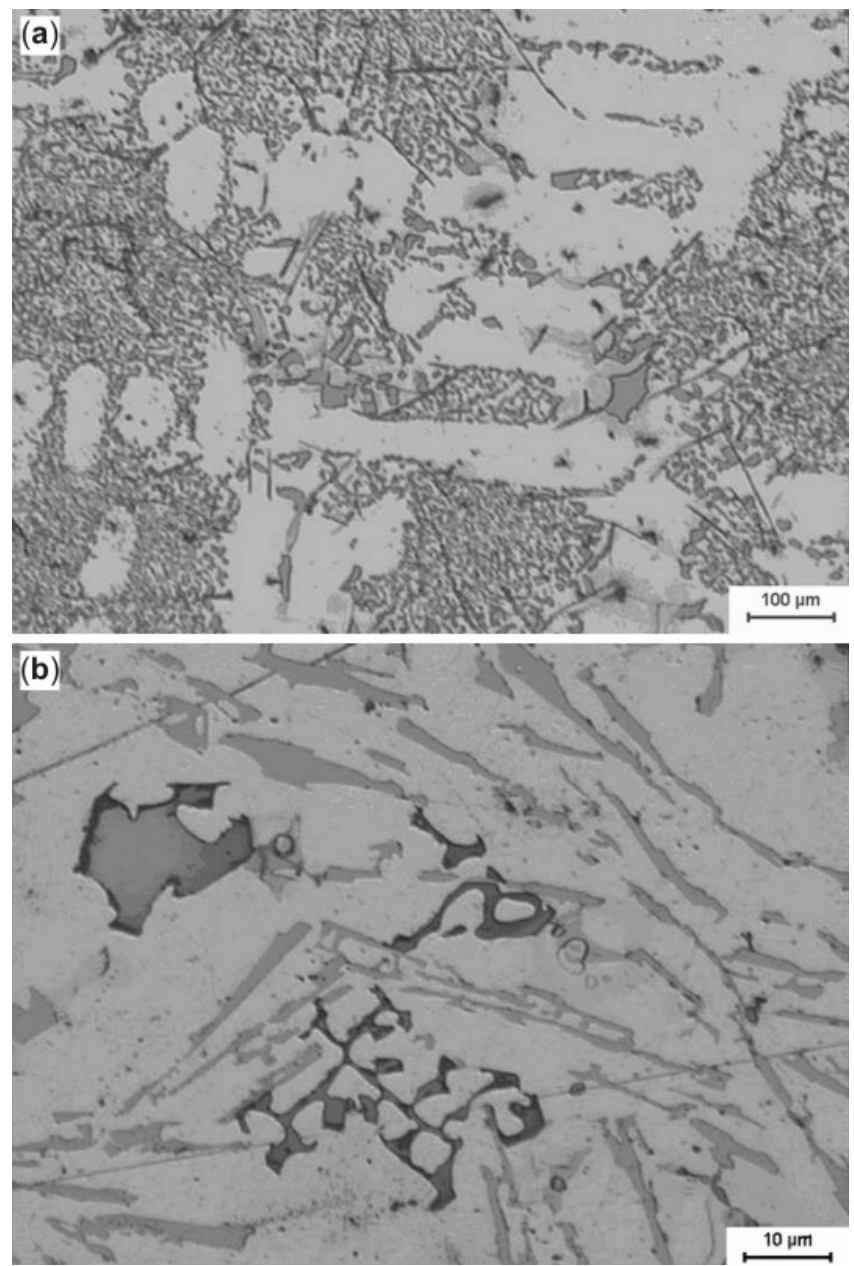

Figure 1. Microstructure of as-cast A2 alloy (a) dendritic structure and (b) distribution of silicon platelets (grey) and fine intermetallic particles. caused by the formation of polynary eutectic phases with low melting points. This type of eutectic phases are present in the material when the copper content is higher than $2 \%$. Increasing the amount of copper in the alloy causes increase of these phases (Wang et al 2003).

\subsection{Hardness}

To understand the effect of copper content and heat treatment, hardness values of alloys were measured both in as cast and heat treated conditions. The dimensions of the hardness specimens were $2 \times 2 \times 2 \mathrm{~cm}$ and all the specimens were prepared in the usual metallographic manner, $3 \mu \mathrm{m}$ diamond particles were used for final polishing. Figure 6 shows the graphical representation of hardness values of the alloys, all the given values are average of 5 measurements. It is obvious that increasing the $\mathrm{Cu}$ amount in the alloys increases the hardness with or without heat treatment. Figure 6 also shows that aging heat treatment increases hardness nearly $100 \%$ for alloy
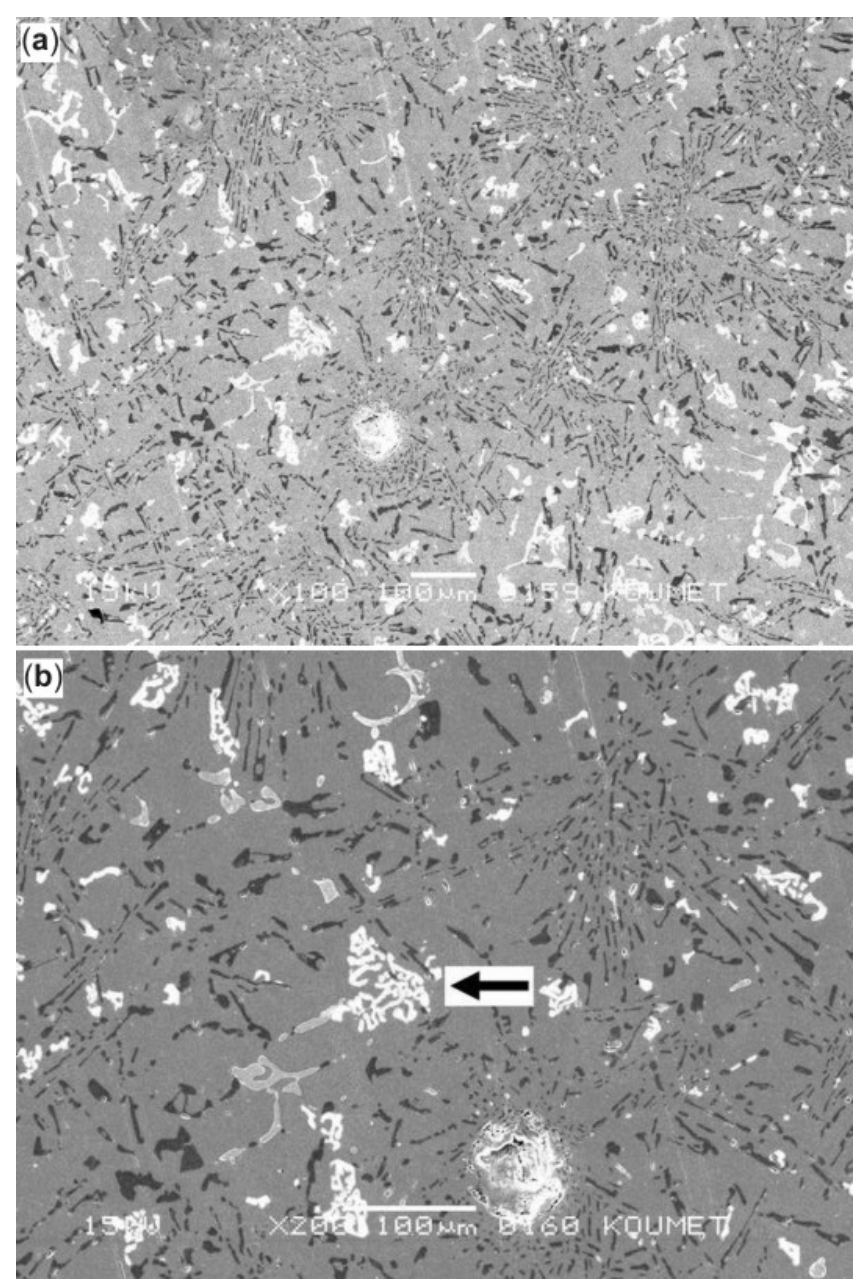

Figure 2. (a) SEM microstructure of as-cast A5 alloy and (b) white contrasted intermetallic phase 

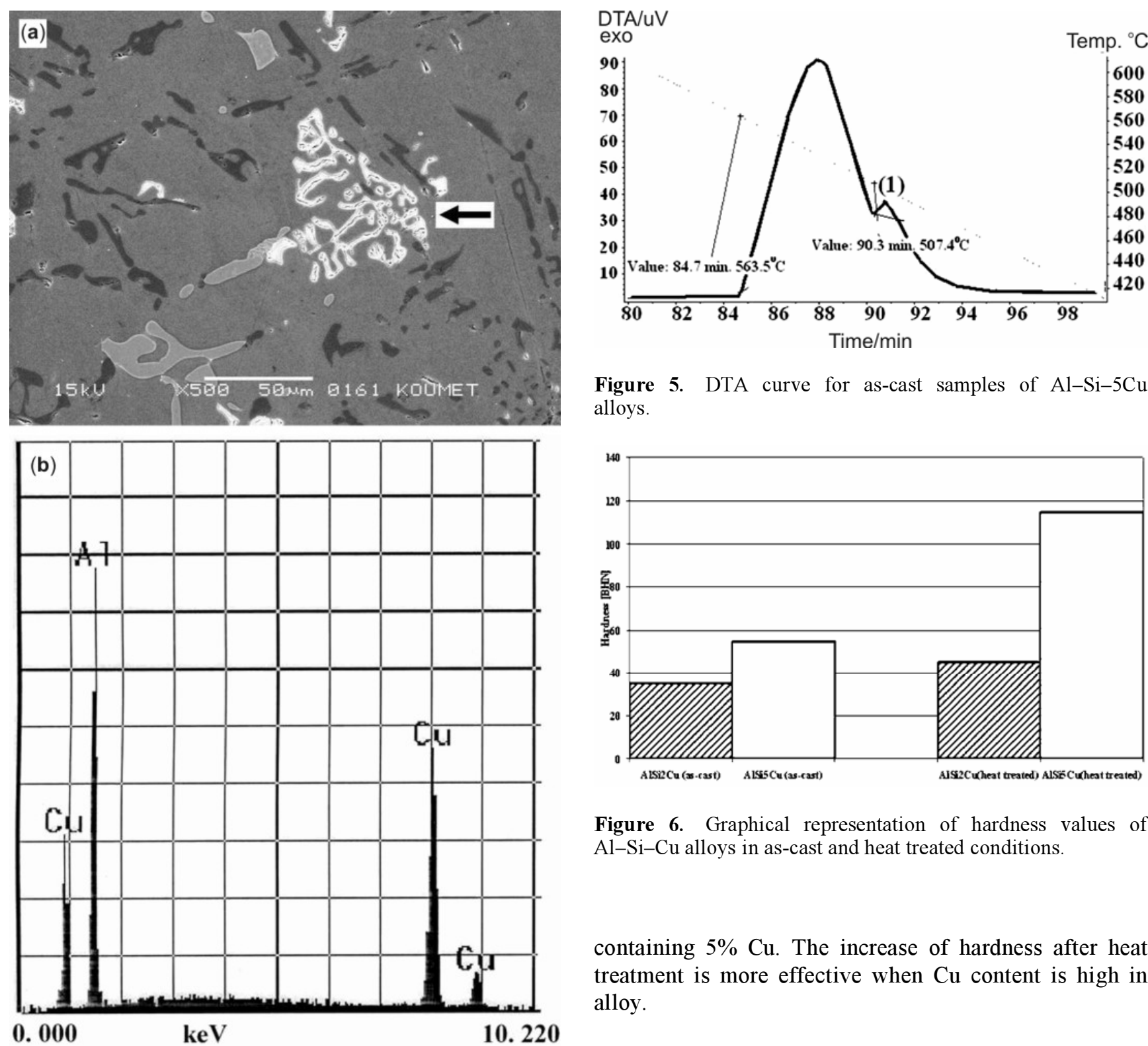

Figure 5. DTA curve for as-cast samples of $\mathrm{Al}-\mathrm{Si}-5 \mathrm{Cu}$ alloys.

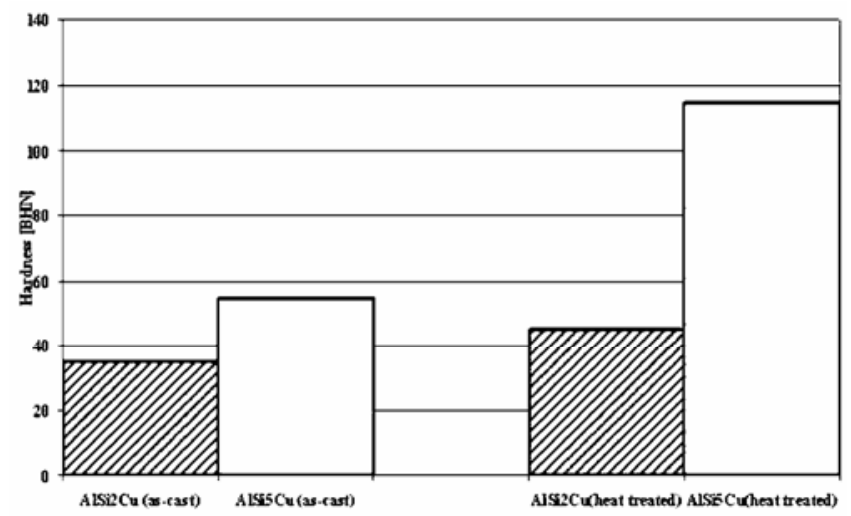

Figure 6. Graphical representation of hardness values of $\mathrm{Al}-\mathrm{Si}-\mathrm{Cu}$ alloys in as-cast and heat treated conditions.

containing $5 \% \mathrm{Cu}$. The increase of hardness after heat treatment is more effective when $\mathrm{Cu}$ content is high in alloy.

Figure 3. (a) Microstructure of the intermetallic particle and (b) energy dispersive X-ray analysis of the white contrasted particle in figure 2(b) (arrowed).

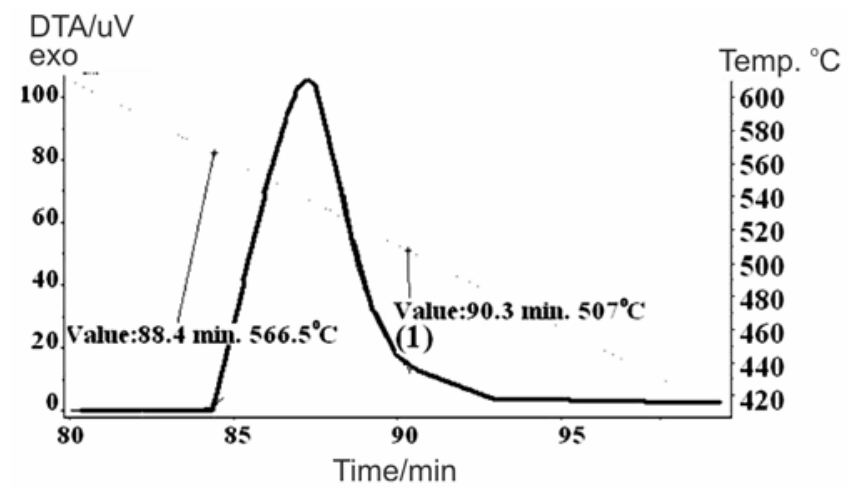

Figure 4. DTA curve for as-cast samples of $\mathrm{Al}-\mathrm{Si}-2 \mathrm{Cu}$ alloys.

\section{Conclusions}

(I) Large precipitates of stable $\mathrm{Al}_{2} \mathrm{Cu}$ phases were found in the solidified alloys.

(II) Mechanical properties of $\mathrm{Al}-\mathrm{Si}-\mathrm{Cu}$ alloys largely depend on the heat treatment. Thus, characteristics of heat treatment play a vital role for a good combination of microstructure and mechanical properties. Copper content in $\mathrm{Al}-\mathrm{Si}-\mathrm{Cu}$ alloys affect the mechanical properties. By increasing copper content, hardness increases due to precipitation hardening. It is found that increasing copper content from 2 to $5 \%$ increases from $55 \mathrm{HB}$ to $115 \mathrm{HB}$.

(III) Peak 1 in DTA appears when $\mathrm{Cu}$ content is more than $2 \%$. The height of peak 1 increases due to increasing $\mathrm{Cu}$ content. This means that polynary eutectic phases are formed when $\mathrm{Cu}$ content is more than $2 \%$ and its amount is increasing with increasing $\mathrm{Cu}$ content. 
(IV) For $\mathrm{Al}-\mathrm{Si}-\mathrm{Cu}$ alloys, the restrictive solution temperature avoiding grain boundary melting decreases with increasing $\mathrm{Cu}$ content. For alloys with more than $2 \mathrm{wt} . \%$ $\mathrm{Cu}$, suitable temperature is $500^{\circ} \mathrm{C}$ (Wang et al 2003).

\section{References}

Guo Z and Sha W 2005 Mater. Sci. \& Eng. A392 449

Haque M and Maleque 1998 J. Mater. Process. Technol. 77122
Kim Y and Buchheit R G 2007 Electrochim. Acta 522437

Li R X, Li R D, Zhao Y H, He L Z, Li C X, Guan H R and Hu Z Q 2004 Mater. Letts 582096

Li X, Li D, Zhao H, He Z, Li X, Guan R and Hu Q 2004 Mater. Letts $\mathbf{5 8} 2096$

Rosliza R, Wan Nik W B and Senin H B 2008 Mater. Chem. \& Phys. 107281

Wang G, Bian X, Wang W and Zhang J 2003 Mater. Letts 4480 1

Zeren M 2005 J. Mater. Process. Technol. 169292 